\title{
Terminología y fraseología del texto técnico en alemán: características y problemas en la aplicación de la traducción automática'
}

\author{
María-Pilar Castillo Bernal \\ pilar.castillo.bernal@uco.es \\ https://orcid.org/0000-0002-2594-2593 \\ Universidad de Córdoba, España
}

Check for

updates

\section{Resumen}

El presente trabajo tiene por objeto aunar la investigación de corte lingüístico con los estudios de corpus y la posedición, de cara a construir una metodología aplicable a la traducción de textos técnicos, y a la didáctica de la misma. De manera específica, se busca profundizar y contextualizar la investigación en torno a las características del lenguaje técnico en alemán, explorar las técnicas de trasvase al español de la terminología y la fraseología especializadas en el marco de la traducción profesional y comprobar si los resultados de la traducción automática obtienen una calidad suficiente para aplicar la traducción automática en el campo de la tecnología nuclear. Para ello, se ha compilado un corpus de textos especializados y se han extraído las unidades terminológicas más frecuentes con ayuda de la herramienta Sketch Engine. Una vez analizadas, se someten a traducción automática para comprobar las inadecuaciones con respecto a los términos individuales, términos multipalabra y formas verbales. Los resultados muestran, por un lado, la complejidad y la variación presentes en el lenguaje de especialidad de este ámbito y, por otro, que la traducción automática no alcanza una calidad suficiente para cumplir la función de las traducciones profesionales, si bien podría usarse con fines informativos. El traductor al español debe tener competencia tanto lingüística como textual y pragmática para aplicar las técnicas y estrategias necesarias para llevar a cabo una traducción funcional.

Palabras clave: traducción de textos técnicos; traducción alemán-español; terminología; fraseología; traducción automática; posedición de traducciones.

\section{Terminology and Phraseology of Technical Texts in German:} Characteristics and Problems in the Use of Machine Translation

\begin{abstract}
This paper aims to combine linguistic research with corpus studies and post-editing in order to construct a methodology applicable to the translation of technical texts and the teaching thereof. Specifically, it intends to deepen and contextualise research into the characteristics of technical language in the German language, to explore the techniques for transferring specialised terminology and phraseology into Spanish within the framework of professional translation, and to check whether the results of machine translation are of sufficient quality to be applied to the field of nuclear technology. To this
\end{abstract}

1 Esta investigación es parte de un proyecto de habilitación en curso en la Universidad de Córdoba (España) con el título “TTCORP: Elaboración de corpus paralelos de traducciones técnicas alemán-español”. [2021-2022] 
end, a corpus of specialised texts has been compiled and the most frequent terminological units have been extracted with the help of Sketch Engine. Once analysed, they are machine translated to check for inadequacies with regard to single terms, multi-word terms and verb forms. The results show, on the one hand, the complexity and variation present in the specialised language of this field and, on the other hand, that machine translation is not of sufficient quality to fulfil the function of professional translations, although it could be used for information purposes. Translators into Spanish must be linguistically, textually, and pragmatically competent in order to apply the techniques and strategies necessary to carry out a functional translation.

Keywords: Translation of technical texts; German-Spanish translation; terminology; phraseology; machine translation; machine translation postediting.

\section{Terminologie et phraséologie des textes techniques en allemand: caractéristiques et problèmes de l'application de la traduction automatique}

\section{Résumé}

L'objectif de cet article est de combiner la recherche linguistique avec des études de corpus et la post-édition afin de construire une méthodologie applicable à la traduction de textes techniques et à la didactique de la traduction. Concrètement, il s'agit d'approfondir et de contextualiser la recherche sur les caractéristiques du langage technique en allemand, d'explorer les techniques de transfert de la terminologie et de la phraséologie spécialisées en espagnol dans le cadre de la traduction professionnelle et de vérifier si les résultats de la traduction automatique sont de qualité suffisante pour appliquer la traduction automatique dans le domaine de la technologie nucléaire. Pour ce faire, un corpus de textes spécialisés a été compilé et les unités terminologiques les plus fréquentes ont été extraites à l'aide de l'outil Sketch Engine. Une fois analysées, elles sont soumises à une traduction automatique afin de vérifier l'absence d'inadéquations en ce qui concerne les termes simples, les termes à plusieurs mots et les formes verbales. Les résultats montrent, d'une part, la complexité et la variation présentes dans le langage spécialisé de ce domaine et, d'autre part, que la traduction automatique n'atteint pas une qualité suffisante pour remplir la fonction de traductions professionnelles, bien qu'elle puisse être utilisée à des fins informatives. Le traducteur espagnol doit posséder des compétences linguistiques, textuelles et pragmatiques afin d'appliquer les techniques et stratégies nécessaires à la réalisation d'une traduction fonctionnelle.

Mots clés: traduction de textes techniques ; traduction allemand-espagnol ; terminologie ; phraséologie ; traduction automatique ; post-édition de traductions automatiques. 


\section{Introducción}

La traducción de textos técnicos, más frecuentemente en el binomio científico-técnico, ha sido objeto de numerosos estudios desde mediados del pasado siglo, en aspectos como sus características particulares, el lenguaje científico y técnico o los problemas de traducción (Jumpelt, 1961; Maillot, 1997). En el contexto de los géneros técnicos en lengua alemana y su traducción al español, destacan las obras de Göpferich (1995) y Gamero (2001). Más recientemente, autores como Olohan (2016) o Byrne (2014) han aportado una perspectiva profesional a la traducción científica y técnica, además de ilustrar el uso de nuevas herramientas como la lingüística de corpus en los ámbitos científico y técnico. Precisamente el uso de corpus, junto a la traducción automática y la posedición, han adquirido una creciente importancia en la traducción técnica, de ahí su interés por incorporarlos a la metodología de este trabajo.

En este contexto, se ha verificado una escasez de estudios recientes en el par de lenguas alemán-español sobre los rasgos textuales y su traducción, así como sobre la posedición de los mismos, a pesar de la importancia económica de este sector para el traductor profesional. Por ello, nuestro estudio pretende aplicar la extensa investigación existente en el campo de la traducción técnica a la traducción y la posedición del texto técnico del alemán al español. Con el fin de establecer los principales rasgos terminológicos y fraseológicos de este tipo de textos, se ha recopilado un corpus de estos textos en lengua germana traducidos al español en encargos reales a lo largo de los últimos diez años. La compilación del corpus se hizo con ayuda de la herramienta Sketch Engine. Una vez realizado el análisis contrastivo de los mismos con base en la literatura especializada (Arntz, 2001; Fluck, 1997), se seleccionaron los fragmentos identificados como potencialmente más complejos o problemáticos para someterlos a una traducción automática con el motor DeepL. El objetivo del estudio es determinar qué rasgos prototípicos del texto técnico en alemán son más problemáticos a la hora de aplicar la traducción automática y realizar la posedición en español. Del mismo modo, las conclusiones son relevantes para la enseñanza de la traducción técnica, dada la creciente tendencia al uso de la traducción automática y la posedición en los estudios de traducción e interpretación.

El trabajo está estructurado de la siguiente manera: en el apartado de fundamentos teóricos, se examina la literatura en torno a los rasgos terminológicos y fraseológicos del texto técnico en alemán y algunos trabajos sobre su traducción al español y problemas frecuentes. En el apartado de metodología se exponen los pasos dados y las características del corpus compilado. A continuación, se presentan los resultados tanto del análisis lingüístico como de la aplicación de la traducción automática a los fragmentos seleccionados. Por último, se exponen las conclusiones desde el punto de vista de la traducción y la posedición de textos técnicos, así como la didáctica de las mismas.

\section{Fundamentos teóricos: el alemán técnico y su traducción al español}

Como lengua germánica, el alemán presenta características propias y diferenciadas de las lenguas romances que se manifiestan en el lenguaje científico-técnico. No obstante, algunos de los rasgos terminológicos y estilísticos que exploraremos a continuación pueden darse también en el español especializado (p. ej., el uso de la metáfora en ámbitos científico-técnicos).

\subsection{Rasgos del alemán técnico}

En este apartado se clasifican varios aspectos del uso y la formación de estructuras y vocablos en el lenguaje técnico en lengua alemana. 
En el marco de este trabajo, el adjetivo "técnico" se emplea en el sentido derivado de "tecnología", y no como sinónimo de especializado o de científico, tal como se recoge en Zafio (1996, p. 193). Siguiendo los autores más relevantes, se examinarán los planos léxico-semántico, morfosintáctico y estilístico del lenguaje de las tecnologías.

\subsubsection{Plano léxico-semántico}

En la formación de términos existen peculiaridades de la lengua alemana que pueden plantear dificultades al traductor. Algunas de ellas son, según Fluck (1997, pp. 37-46):

- Polisemia: palabras que reciben en el ámbito científico-técnico un significado distinto al de la lengua general, como se indica en la Tabla 1.

Tabla 1. Términos con significados diferentes en LG (lengua general) Y LE (lengua de especialidad)

\begin{tabular}{l:l}
\multicolumn{1}{c}{ LG } & \multicolumn{1}{c}{ LE } \\
\hdashline Mutter = madre & Mutter = tuerca \\
\hdashline Speicher = almacén & $\begin{array}{l}\text { Speicher = memoria } \\
\text { (informática) }\end{array}$ \\
\hdashline Pilgern = peregrinar & $\begin{array}{l}\text { Pilgern = laminado en frío } \\
\text { Galgen = patíbulo }\end{array}$ \\
& $\begin{array}{l}\text { Galgen = soporte para } \\
\text { micrófono }\end{array}$
\end{tabular}

- Normalización o estandarización de los términos: debido a la polisemia, resulta necesario definir los conceptos técnicos, en textos como normas o manuales: "Rauschen $=$ Schallsignal statistischer Natur, bei dem nur ein kontinuierliches Intensitätsspektrum angegeben werden kann". ${ }^{2}$

- Variación en el plural o el género de los términos en el lenguaje especializado con respecto al lenguaje general: Mutter: plural Mütter (LG), Muttern (LE); Moment: género

2 Fuente: norma DIN 1320, "Akustik, Grundbegriffe". masculino (LG), género neutro (LE). En la Tabla 2 se presenta un ejemplo de diferenciación según el uso del término.

Tabla 2. Variación en los términos según la situación de uso

\begin{tabular}{l|l}
\multicolumn{1}{c}{ Situación de uso } \\
$\begin{array}{l}\text { Manual de técnica de } \\
\text { datos }\end{array}$
\end{tabular}$\quad \begin{gathered}\text { Término utilizado } \\
\text { Instrucción de trabajo } \\
\begin{array}{l}\text { Puesto de trabajo } \\
\text { D }\end{array}\end{gathered}$

- Duplicidad terminológica, debido a la coexistencia de términos grecolatinos (cultismos) y germánicos (comprensibles para el público no especializado): Kompressor / Verdichter; Generator / (Strom-) Erzeuger.

Junto a estas características de polisemia y variación, la constante evolución del lenguaje técnico debido a los avances en los distintos campos da lugar a diversos procedimientos de creación neológica. Respecto a los procesos de formación de nuevos términos, Fluck (1997, p. 47) distingue cinco grandes mecanismos:

1. Terminologización de vocablos del lenguaje común (metáfora, metonimia, generalización o concretización del significado). Sobre este mecanismo apunta Arntz (2001, p. 80) que cada palabra o conjunto de palabras de la lengua general puede terminologizarse e incluso adquirir distintos significados en diversas lenguas de especialidad, como sucede con la palabra Wurzel en matemáticas, lingüística u odontología, o los términos físicos Raum, Zeit, Bewegung.

Por lo que respecta a la metáfora en la terminología técnica, Fluck indica que proviene habitualmente de ámbitos cotidianos, ${ }^{3}$ y distingue diferentes tipos, tal como se observa en los siguientes ejemplos:

3 Cfr. Jakob (1998, p. 146, apud. Arntz, 2001, p. 80): Las fuentes de metáforas técnicas más prolíficas son los órganos del cuerpo humano, objetos cotidianos 
- Metáfora de forma: Anker, Trommel, Dorn

- Metáfora de función/lugar: Bett, Brücke, Tisch

- Metáfora de función/forma: Kappe, Fenster, Krokodil

- Metáfora de movimiento: Kissen, Schlitten, Flügel

- Metáfora visual: Mönchsschrift, Zwiebelfisch

La metonimia es frecuente en la utilización de los nombres propios de inventores o descubridores, tanto en su forma sustantiva como derivada: Faraday-Effekt, Ohmsches Gesetz, Volt, Watt, Celsius, Diesel-Motor, röntgen, mientras que la generalización o concretización del significado puede dar lugar a la polisemia no solo con el lenguaje general, sino también entre diferentes disciplinas especializadas. Esto lo explica Fluck (1997, p. 52) cuando destaca que Strom es un término especializado de la mecánica, de la termodinámica y de la electrotécnica dentro de la física, pero también de la geografía. Sin embargo, esta polisemia no suele presentar dificultades, ya que se añaden además componentes aclaratorios o definitorios, como en el caso de elektrischer Strom.

2. Empleo de vocablos de otras lenguas (préstamo, calco). Entre los préstamos (Entlehnungen) se cuentan los términos incorporados al alemán sin (apenas) modificaciones desde lenguas como el latín (Corpus), el griego (Analyse, Atom) o el inglés (Computer, Laser). Asimismo, existen préstamos parciales, especialmente en composición con vocablos de raíz germánica: infrarot, Atomspaltung, $L a$ serstrahl. Por otro lado, los calcos (Lehnübersetzungen) se constituyen como traducciones

(Bett, Brille, Gabel), animales, órganos animales, plantas y sus partes. literales: Überschallgeschwindigkeit (supersonic velocity), Sauerstoff (oxygenium).

3. Derivación: mediante sufijos, prefijos o semiprefijos y semisufijos ${ }^{4}$ como puede observarse en las Tablas 3 a 6, adaptadas de vDI 2276,4, apud. Fluck (1997, p. 60).

Otros prefijos son: un- (negación), ab- (retirar, evacuar), de- (des-), vor- (pre-), aus-

Tabla 3. Sufijos del sustantivo

\begin{tabular}{|c|c|c|}
\hline Suf. & Significado & Ejemplos \\
\hline -er & $\begin{array}{l}\text { Agente, } \\
\text { dispositivo }\end{array}$ & Schweißer, Regler \\
\hline -ung & Proceso, objeto & Kühlung, Verpackung \\
\hline -heit & Cualidad & Weichheit \\
\hline -keit & Cualidad & Löslichkeit \\
\hline -ion & $\begin{array}{l}\text { Proceso, acción, } \\
\text { cualidad, estado }\end{array}$ & $\begin{array}{l}\text { Induktion, Ventilation, } \\
\text { Gravitation }\end{array}$ \\
\hline -ie & $\begin{array}{l}\text { Cualidad, Campo } \\
\text { de especialidad, } \\
\text { abstracción }\end{array}$ & $\begin{array}{l}\text { Symmetrie, Metallurgie, } \\
\text { Theorie }\end{array}$ \\
\hline -tät & $\begin{array}{l}\text { Cualidad, estado, } \\
\text { abstracción }\end{array}$ & $\begin{array}{l}\text { Elektrizität, Elastizität, } \\
\text { Produktivität }\end{array}$ \\
\hline -ik & $\begin{array}{l}\text { Campo científico, } \\
\text { instalación, } \\
\text { método }\end{array}$ & $\begin{array}{l}\text { Botanik, Hydraulik, } \\
\text { Dialektik }\end{array}$ \\
\hline -ismus & $\begin{array}{l}\text { Unidad concreta, } \\
\text { abstracción }\end{array}$ & $\begin{array}{l}\text { Magnetismus, } \\
\text { Mechanismus }\end{array}$ \\
\hline
\end{tabular}

Tabla 4. Sufijos del adjetivo

\begin{tabular}{|c|c|c|}
\hline Suf. & Significado & Ejemplos \\
\hline -bar & $\begin{array}{l}\text { Capacidad, } \\
\text { susceptible de }\end{array}$ & dehnbar, drehbar \\
\hline -haft & Tener, tipo & fehlerhaft, roboterhaft \\
\hline -lich & $\begin{array}{l}\text { Cercanía, } \\
\text { tendencia }\end{array}$ & rötlich, weichlich \\
\hline -sam & $\begin{array}{l}\text { Tendencia, } \\
\text { capacidad }\end{array}$ & wirksam, biegsam \\
\hline -mäßig & Tipo, según & $\begin{array}{l}\text { regelmäßig, } \\
\text { ordnungsmäßig }\end{array}$ \\
\hline -los & Ausencia & nahtlos, geruchlos \\
\hline -frei & Libre de & rostfrei, holzfrei \\
\hline
\end{tabular}

4 Para una lista exhaustiva de Suffixe, Präfixe, Halbsuffixe y Halbpräfixe, cfr. Reinhardt et al. (1978, pp. 60-178). 
Tabla 5. Sufijos del verbo

\begin{tabular}{|c|c|}
\hline Suf. & Ejemplos \\
\hline -en/-ieren & $\begin{array}{l}\text { locken, fetten, faxen, formatieren, } \\
\text { signalisieren }\end{array}$ \\
\hline $\begin{array}{l}\text {-isieren / } \\
\text {-fizieren }\end{array}$ & $\begin{array}{l}\text { automatisieren, kristallisieren, elektrifizie- } \\
\text { ren, klassifizieren }\end{array}$ \\
\hline
\end{tabular}

(completamente, hacia afuera), ein- (hacia adentro, in). Algunos prefijos y sufijos germánicos son intercambiables con la versión internacional: intermolekular $=$ zwischenmolekular. En el caso de los semiprefijos y semisufijos, se trata de elementos que no en todos los casos se identifican claramente como afijos, sino que se encuentran a medio camino entre estos y los elementos de un compuesto, por lo que también se denominan semiafijos, como es el caso de $z u$ sammen-y -matismus (Reinhardt et al., 1978, p. 60).

4. Construcción de términos plurilexemáticos (así como grupos léxicos) o composición. Según Arntz (2001, p. 81), la construcción de sustantivos compuestos es un proceso de producción léxica especialmente productivo en alemán. Las combinaciones más importantes en la composición son:

- Sustantivo + sustantivo: Zahnrad, Glasfaser, Elektronenröhre
- Verbo + sustantivo: Fräsmaschine, Biegemoment, Schmelzofen

- Adjetivo + sustantivo: Hochofen, Edelmetall, Grauguß

- Adverbio + sustantivo: Außenantenne, Innenanlage, Querschnitt

- Adjetivo + verbo: hartlöten, kaltwalzen, dauertesten

- Preposición + sustantivo: Durchmesser, Überstrom, Innenwiderstand

- Numeral + sustantivo: Dreieck, Zweipol, Viergespann

- Sigla + sustantivo: HF-Gebiet, NF-Trafo, UHF-Gebiet

Como nexo de unión entre palabras compuestas, existen las siguientes posibilidades:

- Sin nexo: Stoff / wechsel

- Omisión de la "e": Zell(e)aufbau

- "S" de unión (cuando el primer término acaba en -heit, -keit, -ion, -ling, -schaft, -tät, -ung, o en otros casos): Spannungsübertragung, Elektrizitätsträger, Gewichtseinheit

- "E" de unión: Tageförderung

- "N" de unión: Scheibenbock

- Plural en el primer término: Räderschema

- Guion: Diesel-Motor

Tal como señala Fluck (1997, p. 65), en los lenguajes especializados de las ciencias

Tabla 6. Prefijos más frecuentemente utilizados, también en el lenguaje general

\begin{tabular}{|c|c|c|c|c|c|c|c|}
\hline & be- & ent- & er- & ge- & miß- & ver- & zer- \\
\hline Proceso que comienza o transcurre & & $x$ & $x$ & & & & \\
\hline Proceso o estado que se evita o acaba & & $x$ & & & & & \\
\hline Consumir, destruir, desaparecer & & & & & & $x$ & $x$ \\
\hline Modificar estado & & & & $x$ & & $x$ & \\
\hline Unir o cerrar & & & & & & $x$ & \\
\hline Poner, revestir & $x$ & & & & & $x$ & \\
\hline Separar, sustituir & & $x$ & & & & $x$ & $x$ \\
\hline Completar & $x$ & $x$ & $x$ & & & $x$ & \\
\hline Reforzar, referir & $x$ & & & & & $x$ & \\
\hline Deficientemente & & & & & $x$ & $x$ & \\
\hline
\end{tabular}


naturales y de la técnica se dan con relativa frecuencia compuestos de tres o más palabras. Algunos ejemplos de estos compuestos plurilexemáticos proporcionados por el autor son: Lochkartenziehkartei, Drehstromkurzschlußläufermotor, y, más raramente, compuestos de gran extensión del tipo: Schmalrollen-Glühband-Längsbrenn-Schneidmaschine. Una particularidad del alemán es que también los adjetivos, adverbios y verbos admiten composición para describir cualidades y procesos complejos. Así: punktschweißen, warmbiegen, federleicht, dieselelektrisch. Por otro lado, los grupos léxicos consisten en agrupaciones que constituyen una unidad sintáctica terminológica. Se presentan en las siguientes formas:

- Adjetivo + sustantivo: elektronische Datenverarbeitung

- Participio (de presente o de pasado) + sustantivo: störendes Geräusch, computergestützte Übersetzung

- Sustantivo + sintagma preposicional: Übertragungsgeschwindigkeit von Informationen

- Nombre propio declinado + sustantivo: Faradayscher Käfig

- Sustantivo + construcción de genitivo: Unterdruckhöhe des unterirdischen Wassers

Los grupos léxicos son más frecuentes en lenguas como el inglés, el francés y el español, mientras que en alemán predominan los compuestos (Arntz, 2001, pp. 81-82). Especialmente en las lenguas romances, abundan los grupos léxicos de tipo sustantivo + preposición + sustantivo (grasa de soldar - Lötfett; temple por inducción - Induktionshärten), o sustantivo + adjetivo (central nuclear-Kernkraftwerk). Ocasionalmente, estos grupos alcanzan una complejidad que puede hacer dudar de su condición de término (barrera óptica por luz infrarroja modulada). Los compuestos, si bien posibles, son menos frecuentes en español que en el caso del alemán. Algunos ejemplos son: coche-grúa, camión-grúa (Autokran), buque cisterna (Tankschiff) o rayo láser (Laserstrahl).

5. Procedimientos de abreviación: las siglas, acrónimos y abreviaturas son frecuentes en el alemán científico-técnico. ${ }^{5}$ Tal como señala Fluck (1997, p. 81), simplifican las construcciones complejas y alivian visualmente las unidades léxicas. Algunas de las posibles formas de abreviación son:

- Omisión de la primera parte: Abdeckplatte (Klemmenabdeckplatte)

- Omisión de la parte central: Klemmenplatte (Klemmenabdeckplatte)

- Acrónimos:DIN(DeutscheIndustrie-Norm)

- Unión de elementos de varias palabras: Persil (Perborat y Silikat)

- Siglas, en ocasiones unidas a palabras compuestas: HF-Signal (Hochfrequenzsignal)

- Abreviación semántica: Rechner (Rechnermaschine)

\subsubsection{Plano morfosintáctico}

Jiménez Serrano (2002, p. 115) cita la frecuencia significativa de compuestos nominales con diversos elementos en las lenguas germánicas, que plantean problemas complejos de traducción y equivalencia y toman las siguientes formas:

- Sintagmas preposicionales

- Cadenas de sintagmas preposicionales

- Sustantivos modificados por oraciones de
relativo
- Sustantivos modificados por gerundios
- Combinaciones de las formas anteriores

Sustantivos modificados por oraciones de
relativo
Sustantivos modificados por gerundios
Combinaciones de las formas anteriores

- Sustantivos modificados por oraciones de
- Suativo
- Combintinos modificados por gerundios
-

- Sustantivos modificados por oraciones de
relativo
- Sustantivos modificados por gerundios
- Combinaciones de las formas anteriores

5 Muestra de ello son las numerosas compilaciones y publicaciones al respecto (cfr. Fluck, 1997, p. 72). 
Un ejemplo sería la frase: Nach Ablauf der eingestellten Nachladezeit erfolgt die Umschaltung auf Ladeerhaltung. En el caso del alemán, estas construcciones a menudo aparecen antepuestas al núcleo de la oración. Su acumulación puede entrañar no solo "una gran rémora para el proceso traductor (en este caso hacia el espanol), sino una traba innecesaria para la lectura del texto original" (2002, p. 116), por lo que numerosos manuales de redacción técnica recomiendan moderar su uso.

Además de estas particularidades morfosintácticas de la lengua alemana que pueden presentar dificultades al traductor, Sturm y Pradas (2015, pp. 566-567, siguiendo a Stolze, 1999) enumeran las siguientes:

- Estilo impersonal: empleo de pronombres indefinidos (man, es), oraciones subordinadas en forma de construcciones infinitivas o participios, alta frecuencia de construcciones pasivas. El uso de las pasivas (Köhler, 1981, p. 246, apud. Fluck, 1997, p. 92), es de un $35 \%$ en textos técnicos en alemán, frente a un $9 \%$ en los textos generales.

- Predominio del estilo nominal frente al estilo verbal, "ya que los sustantivos dirigen la atención del lector hacia los objetos y los estados de la cuestión".

- Formas más frecuentes para instruir y prohibir: infinitivo imperativo, imperativo directo, verbo modal + infinitivo, construcciones infinitivas $($ sein $+z u+$ infinitiv / lassen + sich + infinitiv).

- Formas instructivas impersonales con valor pasivo: construcciones infinitivas y de participio, estructuras pluriverbales (Funktionsverbgefüge) con sustantivación de los verbos, de manera que no se puede identificar un sujeto activo.

En el caso de la voz pasiva, se emplea tanto la pasiva de proceso (Vorgangspassiv: etwas wird gemacht) como la de estado (Zustandspassiv: etwas ist gemacht), con las subsiguientes implicaciones semánticas y formales, como en el siguiente ejemplo (Fluck, 1997, p. 93): “Der Einsteigeraum wird zu den Sitzen durch halbhohe Wände abgetrennt, an denen gleichzeitig die Haltestangen befestigt sind."

\subsubsection{Plano estilístico}

La redacción de los textos científico-técnicos evoluciona con el paso del tiempo, para adaptarse a las convenciones de cada época. De este modo, Fluck (1997, pp. 82-83) indica que la longitud media de las oraciones en el texto científico-técnico en alemán se ha reducido de 28,5 palabras a 16,83 desde el s. XIX. Por su parte, Eurrutia (2002, p. 52) destaca la preferencia de los científicos por frases largas, de 28 a 35 palabras de media, si bien la autora recomienda reducir la complejidad oracional y alternar las oraciones largas y cortas para aumentar la eficacia de la comunicación. Al mismo tiempo, se detecta una menor subordinación: las oraciones largas supondrían menos de un $40 \%$ del texto científico y contendrían únicamente una o dos subordinadas, en su mayoría unidas mediante parataxis. Las subordinadas más frecuentes son, según Fluck (1997) son:

- Oraciones de relativo: casi el $50 \%$ de todas las subordinadas

- Oraciones de complemento directo con dass: $24 \%$

- Condicionales: $12 \%$

- Causales: $7 \%$

Por otro lado, se tiende a sustituir la subordinación por sintagmas preposicionales (Fluck, 1997, p. 105), de los cuales son más frecuentes:

- bei: sustituye a las conjunciones subordinadas wenn, falls, als, sobald, sofern 
- durch: sustituye a indem, dadurch, dass, weil, da

- $z u$ : sustituye a damit, so dass.

- nach: sustituye a nachdem, wie, sowie, sobald, danach, dass wenn (+ Perf.), otras

- mit: sustituye a als, indem; dadurch, dass; damit, dass

Otros métodos utilizados para comprimir la información son las enumeraciones y los paréntesis (Fluck, 1997, p. 105). Todo ello deriva en textos concisos, abreviados, compactos y con una gran densidad terminológica e informativa. Por otro lado, para mantener el estilo impersonal y evitar un uso repetitivo de la voz pasiva, se emplean además las siguientes construcciones (Fluck, 1997, pp. 96-98):

- $\quad$ pronombre man: Steine verbindet man durch Mörtel

- pronombre es: Es liegen keine ausreichenden Informationen vor, um das Zertifikat zu verifizieren

- construcciones de infinitivo con sein y lassen: Eisenteile sind durch Farbanstriche vor Korrosion zu schützen / Stahl lässt sich verschweißen

- construcciones reflexivas: In verdünnten Säuren löst sich Uran rasch

- estructuras pluriverbales o Funktionsverbgefüge con los siguientes valores semánticos:

- valor incoativo o ingresivo (comienzo de una acción): an die Arbeit gehen $\rightarrow z u$ arbeiten beginnen

- valor durativo o continuativo: in Bewegung sein $\rightarrow$ sich bewegen

- valor egresivo o de resultado (finalización de una acción): außer Betrieb setzen $\rightarrow$ (eine Maschine) zu arbeiten aufhören lassen

- valor causativo: in Bewegung versetzen $\rightarrow$ bewirken, dass sich etwas bewegt

Además del infinitivo, es frecuente el uso de las demás formas no personales del verbo como son los participios de presente y de pasado:
- Partizip I. die abfließende Stahlmenge das glühende Metall

- Partizip Ir. der ermittelte Diffusionskoeffizient

Especialmente en textos científicos y en concreto en el artículo especializado, se emplea, además del estilo impersonal, la primera persona del plural o la tercera del singular con la denominación "el autor" (o en plural, "los autores") (Reinhardt et al., 1978, p. 179). El uso de la primera persona del plural puede deberse a que el sujeto incluye tanto al emisor como a los receptores, como es el caso en las conferencias o los libros de texto: Wir wissen, dass Eisen bei etwa $3250^{\circ} \mathrm{C}$ siedet; Wir stellen fest...; Wir erhitzen das Gemisch... Asimismo, el plural puede obedecer a que el emisor del texto es un colectivo de autores, como es el caso de un grupo de investigación, una institución científica, o los expertos en la materia en general (Reinhardt, 1978, p. 180).

Finalmente, el estilo del texto científico-técnico viene condicionado por la disciplina en la que se enmarca (Jiménez Serrano, 2002, pp. 118-119). Así, el campo de especialidad y las convenciones textuales del género determinan, en gran medida, los rasgos estilísticos que se emplean en un texto concreto, tal como veremos en los resultados.

\subsection{Problemas de traducción}

En este apartado consideraremos algunos de los escollos más frecuentes en la traducción de textos técnicos, relativos tanto a la terminología como a la fraseología. Con carácter general, Pinchuck (1977, pp. 219-222) enumera los principales errores que pueden darse en una traducción científico-técnica:

- Pérdida de información: omisiones o imprecisiones derivadas de un estilo individualizado (no impersonal) o de una traducción demasiado libre. 
- Falta de inteligibilidad: uso idiosincrático de la lengua o estilo no comprensible para el lector.

- Interferencias entre la lengua origen y la lengua meta: particularidades de la lengua origen que "contaminan" la lengua meta, como es el caso de los falsos amigos.

- Nivel incorrecto: de abstracción, estilo, registros.

- Uso erróneo de la lengua meta: ortografía, mayúsculas y minúsculas, puntuación, errores léxicos, omisiones, imprecisiones.

Con respecto a las interferencias entre la lengua origen (LO) y la lengua meta o lengua terminal (цт), Maillot indica una serie de fenómenos lingüísticos que dificultan la búsqueda de equivalencias entre los términos y las nociones de un idioma y otro (1997, pp. 33-92). Destaca "el error que cometen algunos autores poco o nada conocedores de la traducción científica y técnica, al minimizar la importancia de la polisemia en este campo concreto" (Maillot, 1997, p. 32). Dicha polisemia adquiere diversas manifestaciones:

- Monosemia en Lo y polisemia en tr: el caso más favorable para el traductor es cuando, para varias nociones distintas, la lengua original dispone de términos diferentes para cada una, mientras que la lengua terminal solo posee uno. Por tanto, no se plantea el problema de elegir entre varios términos. (Maillot, 1997, p. 33), como en schweißen y löten para soldar.

- Polisemia en LO y monosemia en LT: por ejemplo, en Leitung (conducto, canalización, cable...).

- Polisemia en Lo y en Lt, como en Welle (eje, onda, ola) y eje (Welle, Achse, Mittellinie)

- Variantes nacionales: alemán de Alemania, de Austria, de Suiza (Spital en Suiza, Krankenhaus en Alemania).
- Duplicidad terminológica: formas internacionales y germánicas, como en los siguientes ejemplos: Refraktion y Brechung; Diffraktion y Beugung, Akustik y Schallehre, Projektionslampe y Lichtwurflampe, Thyratron y Stromtor, Hygrometer y Feuchtmesser, Kollektor y Auffänger, Kommutator y Stromwender.

- Falsos amigos, ${ }^{6}$ como los ya mencionados Generator (Wechselstromgenerator), en español alternador (en electricidad), y Stromerzenger (generador de vapor).

- Parónimos: son términos parecidos dentro de un mismo idioma, pero con significados diferentes: adherencia /adhesión; Sicherheit (seguridad) y Sicherung (fusible).

Por otro lado, en su descripción de la fraseología del texto técnico, Sevilla (2015, p. 246) señala la dificultad de distinguir entre las unidades terminológicas y las unidades fraseológicas (UF), especialmente cuando se trata de compuestos sintagmáticos. Indica que Cabré et al. (1996) denominan a estos compuestos unidades terminológicas polilexemáticas (UTP) y las consideran aparte de las Uf. Por otro lado, Sevilla afirma que las estructuras sintagmáticas (colocaciones y locuciones) podrían traducirse aplicando las técnicas habituales de las UF

[...] si hubiera repertorios de UF especializadas ordenadas por palabra clave o por campos temáticos o si se incluyeran estas UF en los diccionarios terminológicos. Como hasta la fecha no parece sencillo localizar obras de este tipo, el empleo de textos paralelos puede ser la mejor opción para la traducción de colocaciones y locuciones especializadas. Sevilla (2015, p. 252)

Coincidimos con Sevilla en la utilidad de observar la fraseología en contexto, especialmente aquella que resulta más difícil de identificar y

6 Navarro (1997) proporciona una lista de falsos amigos en el lenguaje biosanitario (pp. 35-50). 
que, al contrario que la terminología, no suele encontrarse en diccionarios y otras fuentes lexicográficas especializadas. El autor describe las siguientes UF presentes en el discurso científico-técnico (Sevilla, 2015, pp. 243-248):

- locuciones conjuntivas y prepositivas;

- colocaciones de bajo grado de especialización;

- locuciones verbales y adverbiales con un mayor grado de especialización;

- combinación de colocaciones y locuciones;

- esquemas sintácticos: constan de una parte lexicalizada fija y otra variable no catalogable;

- compuestos sintagmáticos, a los que Cabré et al. (1996) denominan unidades terminológicas polilexemáticas (UTP) y consideran aparte de las UF, como se mencionó anteriormente.

En el presente trabajo nos centraremos en las unidades terminológicas individuales y multipalabra, así como en lass principales formas verbales por constituir estas una particularidad morfosintáctica de la lengua alemana.

\section{Metodología y composición del corpus}

Tal como señalábamos en la introducción, escasean los trabajos recientes sobre la traducción del texto técnico del alemán al español con un enfoque contrastivo en estructuras lingüísticas y problemas concretos. En este contexto, destacamos las investigaciones de Sturm y Pradas (2015) sobre la contaminación del uso del infinitivo alemán con valor imperativo en traducciones al español de textos de energía eólica, el estudio de Müller (2018) sobre la terminología de la eficiencia energética en la tecnología de la construcción, y el trabajo de Bautista (2020) en torno a las diferencias fraseológicas en la traducción de textos médico-farmacológicos del alemán y el inglés al español. Compartimos con
Müller el uso de la herramienta Sketch Engine, si bien en su caso se emplea con el objetivo de elaborar un glosario, y con Bautista el enfoque en las estructuras verbales y en los compuestos plurilexemáticos, dos de las particularidades del lenguaje alemán técnico según los rasgos descritos en el apartado 2.

Para la elaboración del corpus, se han tomado traducciones del alemán al español realizadas en el marco de la colaboración con las centrales nucleares (CC.NN.) Almaraz-Trillo en los últimos diez años. ${ }^{7}$ Tal como señalan Arntz y Picht (1991, p. 226), en los trabajos terminológicos bilingües es esencial que los textos sean homogéneos, por lo que nos hemos centrado en los informes de anomalías detectadas en centrales alemanas y descartado otros géneros textuales técnicos como pueden ser las instrucciones de trabajo. ${ }^{8}$ Dichos informes de anomalías pueden ser de dos tipos: Weiterleitungsnachricht o circular de la Sociedad para la Seguridad Nacional alemana GRS (Gesellschaft für Anlagen- und Reaktorsicherheit) y Erfahrungsauswertung (valoración de experiencia operativa) emitido por la vGB (Vereinigung der Großkraftwerkbetreiber) y la empresa Areva. En Castillo (2016) se presenta una descripción general del género textual circular y sus características, también aplicable a los informes de valoración. Estos documentos presentan la ventaja de que, al referirse a cualquier sistema o componente de centrales nucleares en el que se han detectado anomalías durante labores de mantenimiento o inspección, presentan una gran variedad en cuanto a subcampos de especialidad y terminología técnica. Por otro lado, la función de su traducción es informar a las empresas explotadoras de Cc. NN. en España

7 Para información de la empresa, véase https: / / www.bloomberg.com/profile/ company/6650848Z:SM

8 Para una tipología completa de los géneros técnicos, véase Göpferich (1995) y Gamero (2001). 
de anomalías aplicables a sus centrales, para que se tomen las medidas pertinentes.

Aunque se partía de un corpus inicial de 46 textos en alemán y español, la comprobación de la representatividad mediante el programa ReCor (diseñado por las investigadoras Corpas y Seghiri de la Universidad de Málaga) demostró que tanto el subcorpus alemán como el español eran representativos a partir de 1213 documentos, tal como puede observarse en las Figuras 1 y 2, por lo que finalmente se decidió incluir un total de 26 textos en el corpus EOCORP. En ambas figuras, el gráfico de la izquierda muestra la representatividad del corpus por número de documentos (que se alcanza al llegar a los 12-13 documentos), mientras que el gráfico de la derecha muestra la representatividad del mismo corpus con base en el número de palabras o tokens.

EOCORP es, por tanto, un corpus paralelo (compilado a partir de textos traducidos) bilingüe DE-ES, genérico (basado en un género textual concreto) y no anotado, según la clasificación de Baker (1993). Para procesarlo, los textos originales y traducidos se guardaron como archivos .txt y se alinearon con ayuda del programa LFAligner, tras lo cual las memorias bilingües .tmx resultantes se fusionaron en SDL Trados para a continuación crear el corpus bilingüe EOCORP en el programa Sketch Engine a partir de la memoria fusionada y exportada en formato .tmx. De las varias posibilidades de búsqueda y análisis que ofrece Sketch Engine, seleccionamos las "palabras clave" (opción que extrae los términos individuales más característicos, así como los términos multipalabra más propios de dicho corpus en comparación con un corpus equilibrado $)^{9}$ y la opción "listas de palabras" para realizar una búsqueda de los verbos más

9 En este caso, la herramienta indica que el corpus de referencia utilizado para la comparación es German Web 2013 (deTenTen 13). frecuentes. Nos interesan especialmente los términos individuales y multipalabra compuestos, ya que por su mayor complejidad revisten una mayor probabilidad de resultar problemáticos en la traducción automática. Finalmente, por razones de alcance, de los mil resultados arrojados por defecto por Sketch Engine en cada una de las categorías se seleccionaron un total de 50 términos multipalabra, 50 términos individuales y 50 verbos, dando prioridad a la mayor frecuencia de aparición y a su complejidad morfológica (términos compuestos y formas verbales complejas o prefijadas). A continuación, se extrajeron las traducciones correspondientes con ayuda de la opción "concordancia paralela" de la herramienta, para poder observar los equivalentes y técnicas de traducción empleados por los traductores.

Finalmente, se seleccionaron cinco fragmentos de cada categoría para someterlos a traducción automática con DeepL y así comprobar la calidad y capacidad para gestionar la terminología y fraseología propias del campo de especialidad. Los fragmentos traducidos se compararon con las traducciones humanas del corpus, cuya calidad viene dada por su condición de traducciones profesionales validadas por el cliente. En lo sucesivo, expondremos los resultados de las diferentes categorías analizadas.

\section{Resultados}

\subsection{Resultados del análisis terminológico y fraseológico del corpus}

En los 50 términos individuales de mayor frecuencia, los principales fenómenos terminológicos observados son la composición, el uso de siglas, la polisemia o la terminologización y especialización en el campo concreto del saber. Con respecto a los términos compuestos, se trata tanto de sustantivos como de adjetivos (en este caso, un total de cinco). Llama la 

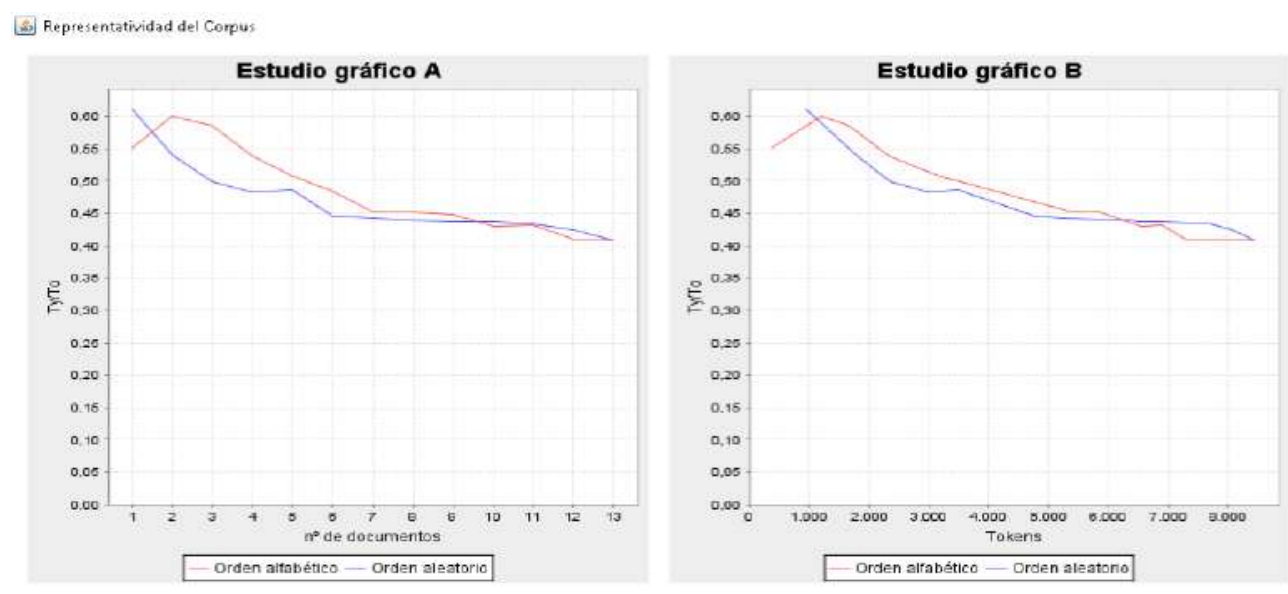

297

Figura 1. Representatividad del subcorpus EOCORP, alemán Fuente: ReCor
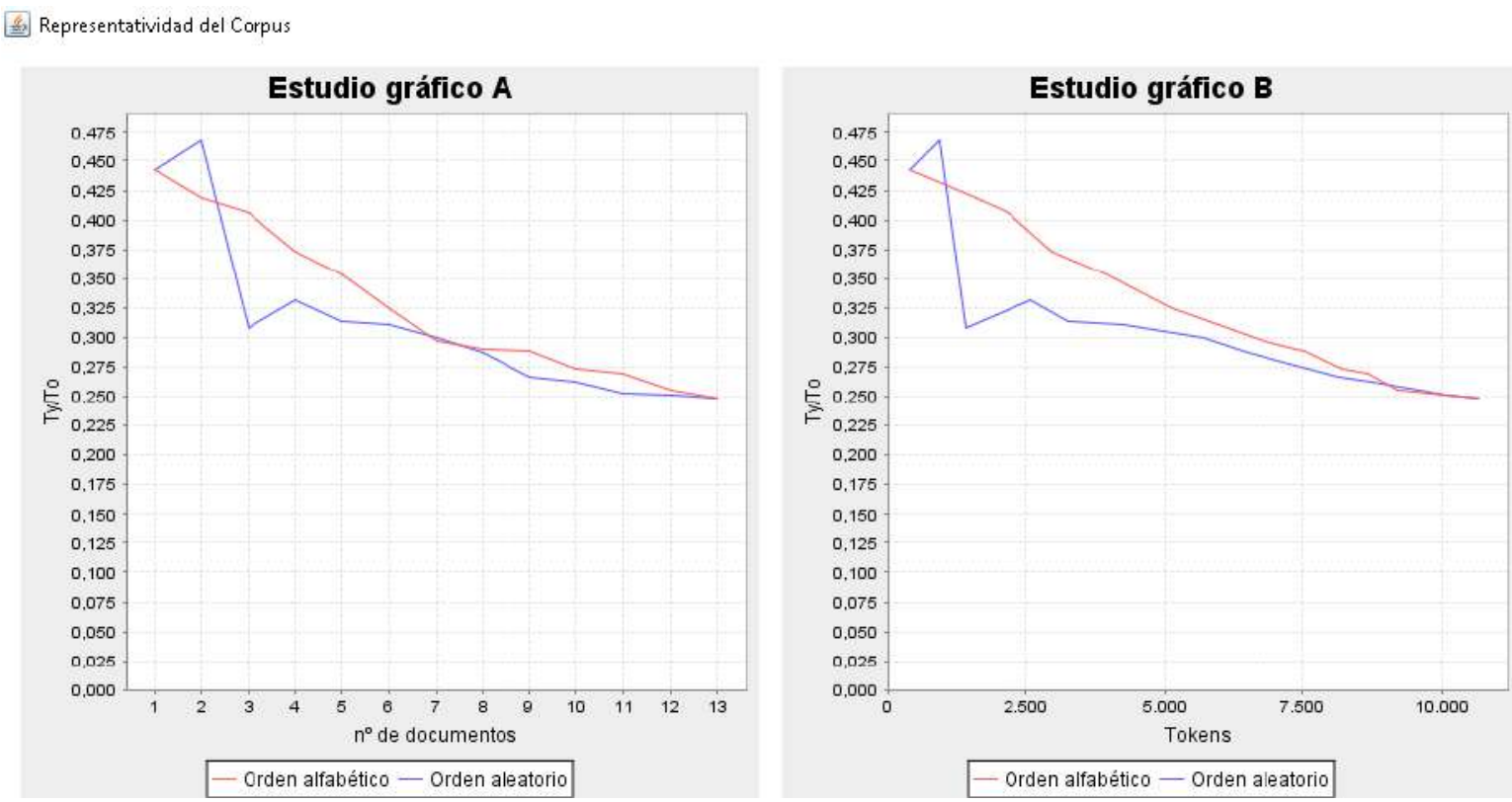

Figura 2. Representatividad del subcorpus EOCORP, español Fuente: ReCor

atención la relativa abundancia de compuestos de tres (13 casos) o incluso cuatro lemas (4 casos), si bien los compuestos de dos lemas son los más frecuentes (un total de 26). En la Tabla 7 se incluyen algunos ejemplos.

Como puede observarse, en el texto traducido el fenómeno más frecuente es la ampliación lingüística por la imposibilidad de formar compuestos en español y el subsiguiente uso de sintagmas preposicionales (por, de), además de ser necesario introducir lemas adicionales de forma puntual para completar el sentido, como es el caso de "cadena de evacuación de calor residual". No obstante, sí existen algunos compuestos parciales como "tensofisuración". Entretanto para la traducción de los adjetivos, en los dos ejemplos que presentamos se recurre a una estructura sintagmática; en el segundo caso (befundbehaftet) se detectan diversas traducciones en el 
Tabla 7. Términos compuestos de mayor frecuencia

\begin{tabular}{|c|c|}
\hline DE & ES \\
\hline Spannungsrisskorrosion & $\begin{array}{l}\text { corrosión por } \\
\text { tensofisuración }\end{array}$ \\
\hline Nachkühlkette & $\begin{array}{l}\text { cadena de evacuación } \\
\text { de calor residual }\end{array}$ \\
\hline Nebenküh/wasserpumpe & $\begin{array}{l}\text { bomba de agua de } \\
\text { refrigeración esencial }\end{array}$ \\
\hline $\begin{array}{l}\text { Regenwasserentwäs- } \\
\text { serungssystem }\end{array}$ & $\begin{array}{l}\text { sistema de drenaje de } \\
\text { agua de lluvia }\end{array}$ \\
\hline mittelträge & de retardo medio \\
\hline befundbehaftet & $\begin{array}{l}\text { con anomalías; que } \\
\text { presenta anomalías; } \\
\text { fisurado }\end{array}$ \\
\hline
\end{tabular}

corpus; en general podemos apreciar más estructuras y términos lexicalizados en el texto original que en las traducciones.

En cuanto a los tipos de términos compuestos, se aprecian los construidos por adjetivo + sustantivo (Feinsicherung, fusible para baja intensidad); adverbio + verbo + sustantivo (Niederhaltefeder, resorte de sujeción); sustantivo + sustantivo (Baugruppe, tarjeta) o verbo + sustantivos (Auslösestromstärke, tensión de desconexión; Brennelement, elemento combustible). Ocasionalmente se observa la elisión de una parte de los compuestos en la traducción al español, como en el caso de Auslösestromstärke, en el que se obvia Stärke (magnitud).

Con respecto a las siglas, se han detectado los siguientes casos que se ejemplifican en la Tabla 8, correspondientes a los códigos de identificación del fabricante Siemens/KMU (como es el caso de ESFAS), a saber, a) siglas creadas ad hoc por el autor de un texto concreto, como es el caso de NHF (Niederhaltefeder); b) siglas de uso más o menos habitual en el género textual, como WKP y WLN; c) siglas de uso extendido en el ámbito de las centrales nucleares como Bнв y $\mathrm{BE} ; \mathrm{d})$ siglas propias del lenguaje técnico en general, como I\&C, que fue el único caso detectado en el que se emplea una sigla en
Tabla 8. Siglas más frecuentes de los sistemas nucleares

\begin{tabular}{|c|c|}
\hline DE & ES \\
\hline ESFAS (Reaktorschutzsystem) & $\begin{array}{l}\text { ESFAS (sistema de } \\
\text { protección del } \\
\text { reactor) }\end{array}$ \\
\hline NHF (Niederhaltefeder) & $\begin{array}{l}\text { resorte de sujeción } \\
\text { de material }\end{array}$ \\
\hline WKP (wiederkehrende Prüfung) & prueba periódica \\
\hline wLN (Weiterleitungsnachricht) & circular \\
\hline BHв (Betriebshandbuch) & $\begin{array}{l}\text { Manual de } \\
\text { operación (M.O.) }\end{array}$ \\
\hline BE (Brennelement) & $\begin{array}{l}\text { E.c. (elemento } \\
\text { combustible) }\end{array}$ \\
\hline Leittechnik & $\begin{array}{l}\text { I\&C (instrumentación } \\
\text { y control) }\end{array}$ \\
\hline
\end{tabular}

español (si bien con un signo ortotipográfico propio de la lengua inglesa, que atribuimos a la influencia de esta lengua en el ámbito técnico) y no en alemán.

Con respecto a la traducción, no se ha detectado la creación de siglas ad hoc en las traducciones. A priori, diríamos que se trata de una práctica más propia de las lenguas germánicas y en concreto más del alemán técnico que del español, ya que este es un idioma generalmente menos propenso al uso de abreviaturas. Se recurre a las siglas en caso de términos de aparición muy frecuente, tales como elementos combustibles (E.C. o EE.CC. en plural).

Otro fenómeno terminológico detectado es la polisemia, como en el caso de Anlagenzustand, ya que Anlage puede referirse en principio a cualquier equipo o instalaciones. Sin embargo, en el contexto de la terminología nuclear suele hacer referencia a la central nuclear en sí, por lo que la mayor parte de las veces se traducirá por central (en el caso de Anlagezustand: estado de la central). También el término Betrieb, que se traduce por "operación", puede hacer referencia tanto al hecho de operar la central en sí (Leistungsbetrieb, operación a potencia) como al departamento de la central encargado de esta tarea, 1lamado "Operación" 
en español. Cabe anotar que esta polisemia puede dar lugar a falsos amigos como Baugruppe (tarjeta eléctrica) o Maschinenhaus, que en la estructura de las centrales nucleares corresponde al edificio de turbina; Maschine es un término enormemente polisémico en alemán técnico y puede hacer referencia a una máquina, un motor o una aeronave, entre otros. Finalmente, un caso curioso de variación lingüística lo observamos en el término propio de "central nuclear" en sí, ya que Kernkraftwerk solo se emplea en ámbitos altamente especializados para evitar las connotaciones negativas de Atomkraftwerk (AKW), que sería el término propio de la lengua común. De manera similar, todos los compuestos que contienen el lema "nuclear" en español se forman en alemán con el término Kern- (núcleo). Con respecto al español, solo existe el término "central nuclear" y sus siglas de uso común en este ámbito C.N. y CC.NN. para el plural. Otra diferencia con el alemán sería que estas siglas solo son reconocidas en el campo de especialidad, mientras que el alemán distingue entre AKW (término conocido por la población en general) y KKW (sigla especializada).
En lo tocante a la fraseología, es de destacar que no todas las unidades detectadas automáticamente por Sketch Engine corresponden a unidades terminológicas fijas; en algunos casos se han extraído términos frecuentes con adjetivos, que no obstante revierten interés para nuestro estudio. Por otro lado, los términos multipalabra correctamente detectados también consisten mayoritariamente en colocaciones de adjetivo (o participio de pasado o de presente) + sustantivo (compuesto), tal como puede observarse en los ejemplos de la Tabla 9.

Además de las estructuras adjetivo + sustantivo, encontramos frecuentes nominalizaciones (sustantivo + genitivo), como en Beschreibung des Vorkommnisses; así como estructuras antepuestas tipo Abschlussglied angesteuerte Komponente. Lo interesante en el caso del español es el carácter variable de algunas fórmulas fraseológicas, tanto en su composición (importancia para la seguridad; importancia desde el punto de vista de la seguridad) como en el orden de sus elementos. Se producen frecuentemente elisiones en unidades terminológicas extensas: "trabajos de mantenimiento preventivo" se en-

Tabla 9. Términos multipalabra

\begin{tabular}{|c|c|}
\hline DE & ES \\
\hline sicherheitstechnische Bedeutung & $\begin{array}{l}\text { importancia para la seguridad; importancia desde el punto de } \\
\text { vista de la seguridad }\end{array}$ \\
\hline wiederkehrende Prüfung & prueba periódica \\
\hline interkristalline Spannungsrisskorrosion & corrosión por tensofisuración intercristalina \\
\hline gesicherte Nebenkühlwasserpumpe & bomba de agua de refrigeración esencial \\
\hline meldepflichtiges Ereignis & suceso notificable \\
\hline Einhalten der Schutzziele & $\begin{array}{l}\text { cumplimiento de los objetivos de protección; integridad de los } \\
\text { objetivos de protección }\end{array}$ \\
\hline Abschlussglied angesteverte Komponente & componentes activados por elemento final de actuación \\
\hline gestaffeltes Sicherheitskonzept & concepto de seguridad escalonado \\
\hline vorbeugende Instandhaltung & $\begin{array}{l}\text { trabajos de mantenimiento preventivo; mantenimiento preventivo; } \\
\text { mantenimiento }\end{array}$ \\
\hline Beschreibung des Vorkommnisses & descripción del suceso \\
\hline Betreiberin des Kernkraftwerkes & explotadora de la central nuclear \\
\hline (zu) betrachtendes Ereignis & suceso contemplable; a tener en cuenta; analizado \\
\hline
\end{tabular}


cuentra también como "mantenimiento preventivo" o simplemente "mantenimiento", a pesar de que en los informes de sucesos ha de precisarse siempre el tipo de mantenimiento que se realiza y existen diversas unidades fraseológicas específicas para cada uno de ellos. La mayor extensión de las unidades fraseológicas en español hace deseable estas elisiones para aligerar el texto, si bien son desaconsejables especialmente en nombres de equipos e instalaciones, como es el caso de "bomba de agua de refrigeración esencial". Se observa también la presencia de sinónimos como Ereignis y Vorkommnis (suceso), que sin embargo en sus respectivas colocaciones no son intercambiables.

En cuanto a los adjetivos y participios que frecuentemente forman parte de estas colocaciones, además de los anteriores destacan los expuestos en la Tabla 10.

Como puede observarse, se alternan los adjetivos de equivalente igual al de la lengua común (empleado, desconectado) con otros cuya traducción adquiere un significado específico o una traducción fija (de operación; esencial; estipulado).

Tabla 10. Adjetivos y participios más frecuentes en colocaciones

\begin{tabular}{|l|l} 
DE & \multicolumn{1}{c}{ ES } \\
spezifikationsgerecht & $\begin{array}{l}\text { enforme a las } \\
\text { especificaciones; conforme a } \\
\text { especificación; conforme } \\
\text { empleado } \\
\text { eingesetzt }\end{array}$ \\
betroffen & afectado \\
aufgetreten & acaecido \\
betrieblich & de operación \\
unzulässig & inadmisible \\
abgeschaltet & desconectado \\
abweichend & desviado, diferente \\
abgesichert & con protección \\
gesichert & esencial \\
abdeckend & estipulado \\
erforderlich & requerido
\end{tabular}

También en las estructuras adjetivales encontramos cierta sinonimia funcional, como es el caso de befundbehaftet (que presenta anomalías) y auffällig geworden (cuya traducción en el corpus es "defectuoso").

También los verbos se caracterizan en este entorno por el significado específico que adquieren. Tal como señala Bautista (2020, p. 26), esto se debe en parte al uso de prefijos que aportan un matiz o acepción adicional, pero también pueden recibir la modificación de adjetivos o adverbios, como en el primer ejemplo de la Tabla 11. Junto a las acciones físicas propias de la operación de sistemas (circular, vaciar, inyectar), encontramos verbos relativos a la gestión de los incidentes (documentar, sujetar, someter) y otros referidos a los procesos de funcionamiento de la central (realizar descargos, reparar, sanear, equipar).

Una vez expuestas las principales características de los términos individuales, multipalabra y verbales extraídos por Sketch Engine, pasaremos a analizar las traducciones automáticas de DeepL para los principales términos de cada categoría.

Tabla 11. Verbos específicos del campo de especialidad

\begin{tabular}{|c|c|}
\hline $\mathrm{DE}$ & ES \\
\hline unscharf schalten & $\begin{array}{l}\text { realizar un descargo } \\
\text { eléctrico }\end{array}$ \\
\hline instandsetzen & reparar \\
\hline durchströmen & circular \\
\hline ablassen & vaciar \\
\hline unterstellen & postularse \\
\hline unterziehen & sujetar a \\
\hline erfassen & documentar \\
\hline ausrüsten & equipar \\
\hline unterliegen & someter \\
\hline ertüchtigen & sanear \\
\hline hinausragen & sobresalir \\
\hline einspeisen & inyectar \\
\hline
\end{tabular}




\subsection{Resultados de la traducción automática}

Examinaremos en primer lugar las traducciones automáticas de términos individuales ya comentados. En el Ejemplo 1, la traducción de Feinsicherung es parcialmente incorrecta, ya que se ha traducido literalmente la primera parte del compuesto Fein-. También la fórmula fraseológica nicht spezifikationsgemäß ha sido incorrectamente traducida de acuerdo con la terminología del campo de especialidad, al igual que Anlagen y Übertragbarkeitsprüfung. Por el contrario, "suceso notificable" ha sido traducido correctamente.

En el Ejemplo 2, se traduce erróneamente Brennelemente y se mantiene la sigla en alemán $\mathrm{BE}$, así como las siglas FR y NHF, que en espa-

Ejemplo 1

\begin{tabular}{|c|c|c|}
\hline DE & . & TA \\
\hline $\begin{array}{l}\text { Verlauf: Auf- } \\
\text { grund von } \\
\text { meldepflichtigen } \\
\text { Ereignissen in } \\
\text { anderen An- } \\
\text { lagen "Nicht } \\
\text { spezifikations- } \\
\text { gemäßer Einsatz } \\
\text { von Feinsiche- } \\
\text { rungen" und der } \\
\text { daraufhin erstell- } \\
\text { ten wLN 2012/01 } \\
\text { wurde im kKG } \\
\text { eine Übertrag- } \\
\text { barkeitsprüfung } \\
\text { durchgeführt. }\end{array}$ & $\begin{array}{l}\text { Transcurso: } \\
\text { Debido a sucesos } \\
\text { notificables en } \\
\text { otras centrales } \\
\text { de "Empleo de } \\
\text { fusibles para } \\
\text { baja intensidad } \\
\underline{\text { no conforme }} \\
\text { a las especi- } \\
\text { ficaciones" y } \\
\text { de la circular } \\
\text { correspondiente } \\
\text { wLN } 2012 / 01, \text { se } \\
\text { realizó en KKG } \\
\text { una prueba de } \\
\text { aplicabilidad. }\end{array}$ & $\begin{array}{l}\text { La historia: } \\
\text { Debido a los } \\
\text { sucesos no- } \\
\text { tificables en } \\
\text { otras plantas } \\
\text { "Uso no espe- } \\
\text { cificado de } \\
\text { fusibles de hilo } \\
\text { fino" y la sub- } \\
\text { siguiente wLN } \\
2012 / 01, \text { se } \\
\text { llevó a cabo } \\
\text { un control de } \\
\text { transferibili- } \\
\text { dad en KKG. }\end{array}$ \\
\hline
\end{tabular}

ñol no resultan comprensibles. Se ha traducido correctamente Stahl-Führungsrohren. En cuanto a Niederhaltefedern, puede considerarse una traducción parcialmente correcta, ya que, aunque la convención sea traducirlo como "resortes", "muelles" es un sinónimo funcional que no impediría la comprensión del texto.

La traducción del Ejemplo 3 es correcta, ya que sicherheitstechnisch ha sido traducido como
Ejemplo 2

\begin{tabular}{|c|c|c|}
\hline DE & ES & TA \\
\hline $\begin{array}{l}\text { Betroffen sind } \\
\text { Brennelemente } \\
\text { (BE) mit Stahl- } \\
\text { Führungsrohren } \\
\text { (FR) und } \\
\text { Niederhaltefedern } \\
\text { (NHF) aus dem } \\
\text { Material Alloy } \\
\text { X-750 aus zwei } \\
\text { Nachlieferungen } \\
\text { (EKK/04/10 und } \\
\text { EKK/05/11). }\end{array}$ & $\begin{array}{l}\text { Los afectados } \\
\text { son elementos } \\
\text { combustibles } \\
\text { (EC) con tubos } \\
\text { guía de acero } \\
\text { y resortes } \\
\text { de sujeción } \\
\text { de material } \\
\text { Alloy X-750 } \\
\text { procedentes } \\
\text { de dos envíos } \\
\text { suplementarios } \\
\text { (EKk/04/10 y } \\
\text { EKk } / 05 / 11 \text { ). }\end{array}$ & $\begin{array}{l}\text { Están } \\
\text { afectados los } \\
\text { conjuntos de } \\
\text { combustible } \\
\text { (BE) con tubos } \\
\text { guía de } \\
\text { acero (FR) y } \\
\text { muelles de } \\
\text { sujeción (NHF) } \\
\text { fabricados } \\
\text { con el material } \\
\text { Aleación } \\
\text { X-750 de dos } \\
\text { entregas } \\
\text { posteriores } \\
\text { (EKK/04/10 y } \\
\text { EKK } / 05 / 11 \text { ). }\end{array}$ \\
\hline
\end{tabular}

"para la seguridad", aunque la palabra "hallazgo" no es convencional en este género y se prefiere "anomalías" para Befunde. Por otro lado, se mantienen las siglas $\mathrm{KB}$ y $\mathrm{KU}$ en alemán, con lo que el receptor no recibe información de los sistemas afectados.

En el Ejemplo 4, vuelve a traducirse incorrectamente Feinsicherung, pero curiosamente sí es correcta en esta ocasión la traducción de nicht spezifikationsgerecht, que era incorrecta en el Ejemplo 1.

Ejemplo 3

\begin{tabular}{|c|c|c|}
\hline DE & ES & TA \\
\hline $\begin{array}{l}\text { Darüber hinaus } \\
\text { wurden Befun- } \\
\text { de in sicher- } \\
\text { heitstechnisch } \\
\text { nicht relevan- } \\
\text { ten Bereichen } \\
\text { des Sicherungs- } \\
\text { bleches von } \\
42 \text { kB-Schrau- } \\
\text { ben und } 16 \\
\text { ku-Schrauben } \\
\text { festgestellt. }\end{array}$ & $\begin{array}{l}\text { Asimismo, se } \\
\text { detectaron } \\
\text { anomalías } \\
\text { en zonas (no } \\
\text { relevantes para } \\
\text { la seguridad) de } \\
\text { la arandela de } \\
\text { seguridad de } 42 \\
\text { tornillos del barri- } \\
\text { lete y } 16 \text { tornillos } \\
\text { de la envolven- } \\
\text { te del núcleo. }\end{array}$ & 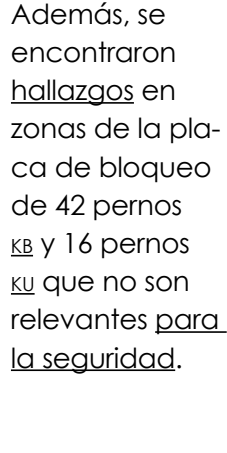 \\
\hline
\end{tabular}


Ejemplo 4

\begin{tabular}{|c|c|c|}
\hline DE & ES & TA \\
\hline $\begin{array}{l}\text { Nicht spezifika- } \\
\text { tionsgerechter } \\
\text { Einsatz von } \\
\text { Feinsicherun- } \\
\text { gen. }\end{array}$ & $\begin{array}{l}\text { Empleo de fusi- } \\
\text { bles para baja } \\
\text { intensidad no } \\
\text { conforme a las } \\
\text { especificacio- } \\
\text { nes. }\end{array}$ & $\begin{array}{l}\text { Utilización de } \\
\text { fusibles de hilo fino } \\
\text { no conforme a las } \\
\underline{\text { especificaciones. }}\end{array}$ \\
\hline
\end{tabular}

Por último, en el Ejemplo 5 no se emplea el término convencional para Baugruppe y tampoco para Behebung; si bien se traducen por sinónimos que, en el caso de "solución", puede ser aceptable, no obstante, la traducción que asegura una correcta comprensión del segundo término por parte del receptor sería "tarjeta".

Ejemplo 5

\begin{tabular}{|c|c|c|}
\hline $\mathrm{DE}$ & ES & TA \\
\hline $\begin{array}{l}\text { Maßnahmen, } \\
\text { Behebung: Aus- } \\
\text { tausch der Bau- } \\
\text { gruppe gegen } \\
\text { Ersatzbaugruppe. }\end{array}$ & $\begin{array}{l}\text { Medidas, } \\
\text { subsanación: } \\
\text { sustitución de } \\
\text { la tarjeta por } \\
\text { una tarjeta de } \\
\text { reemplazo. }\end{array}$ & $\begin{array}{l}\text { Medidas, } \underline{\text { so- }} \\
\text { lución: sustituir } \\
\text { el módulo } \\
\text { por uno de } \\
\text { repuesto. }\end{array}$ \\
\hline
\end{tabular}

Veamos ahora los resultados del análisis fraseológico. En el Ejemplo 6, no es correcta la fraseología de wiederkehrende Prüfungen, pues aunque se emplee un sinónimo no es la fórmula convencional del género textual, y tampoco es correcta la traducción del término Gummikompensatoren.

\section{Ejemplo 6}

\begin{tabular}{|c|c|c|}
\hline $\mathrm{DE}$ & ES & TA \\
\hline $\begin{array}{l}\text { Instandhaltung } \\
\text { und wiederkeh- } \\
\text { rende Prüfungen } \\
\text { an Gummikom- } \\
\text { pensatoren. }\end{array}$ & $\begin{array}{l}\text { Mantenimien- } \\
\text { to y pruebas } \\
\text { periódicas } \\
\text { en fuelles de } \\
\text { goma. }\end{array}$ & $\begin{array}{l}\text { Mantenimiento } \\
\text { e inspecciones } \\
\text { periódicas de las } \\
\text { juntas de dilata- } \\
\text { ción de caucho. }\end{array}$ \\
\hline
\end{tabular}

Con respecto al Ejemplo 7, la traducción de interkristalline Spannungsrisskorrosion no es correcta por el registro empleado ("agrietamiento") ni por el término "intergranular", más propio de otro tipo de materiales.

En el Ejemplo 8, la traducción automática ha malinterpretado gesichert, que traduce por
Ejemplo 7

\begin{tabular}{|c|c|c|}
\hline $\mathrm{DE}$ & ES & TA \\
\hline $\begin{array}{l}\text { Als Schadens- } \\
\text { mechanismus } \\
\text { wurde interkristal- } \\
\text { line Spannungs- } \\
\text { risskorrosion } \\
\text { hervorgerufen } \\
\text { durch ein hohes } \\
\text { Spannungsni- } \\
\text { veau in Kombi- } \\
\text { nation mit einem } \\
\text { aus der Fertigung } \\
\text { resultierenden } \\
\text { interkristallinen } \\
\text { Oberflächenan- } \\
\text { griff identifiziert. }\end{array}$ & $\begin{array}{l}\text { Como meca- } \\
\text { nismo de daños } \\
\text { se identificó la } \\
\text { corrosión por } \\
\text { tensofisuración } \\
\text { intercristalina } \\
\text { por un elevado } \\
\text { nivel de tensión, } \\
\text { en combina- } \\
\text { ción con una } \\
\text { erosión inter- } \\
\text { cristalina de la } \\
\text { superficie con- } \\
\text { secuencia de } \\
\text { la fabricación. }\end{array}$ & $\begin{array}{l}\text { El mecanismo de } \\
\text { daño identifica- } \\
\text { do fue el agrie- } \\
\text { tamiento por } \\
\text { corrosión bajo } \\
\frac{\text { tensión intergra- }}{\text { nular causado }} \\
\text { por un alto nivel } \\
\text { de tensión com- } \\
\text { binado con el } \\
\text { ataque superfi- } \\
\text { cial intergranular } \\
\text { resultante de la } \\
\text { fabricación. }\end{array}$ \\
\hline
\end{tabular}

"con fusible" dando lugar a un sin sentido, e introduce asimismo un contrasentido al traducir "refrigeración auxiliar" en lugar de "esencial".

Ejemplo 8

\begin{tabular}{|c|c|c|}
\hline $\mathrm{DE}$ & ES & TA \\
\hline $\begin{array}{l}\text { Die gesicherte } \\
\text { Nebenküh/was- } \\
\text { serpumpe vel1 } \\
\text { D001 wurde } \\
\text { abgeschaltet. }\end{array}$ & $\begin{array}{l}\text { Se desconectó } \\
\text { la bomba de } \\
\text { agua de refrige- } \\
\underline{\text { ración esencial }} \\
\text { VEl1 D001. }\end{array}$ & $\begin{array}{l}\text { La bomba } \\
\text { de agua de } \\
\frac{\text { refrigeración au- }}{\text { xiliar con fusible }} \\
\text { vel1 D001 se ha } \\
\text { desconectado. }\end{array}$ \\
\hline
\end{tabular}

Con respecto al Ejemplo 9, puede considerarse que se han traducido correctamente tanto Einhalten der Schutzziele como Beherrschung von Störfällen.

Ejemplo 9

\begin{tabular}{|c|c|c|}
\hline DE & ES & TA \\
\hline $\begin{array}{l}\text { Das Einhalten } \\
\text { der Schutzziele / } \\
\text { die Beherrschung } \\
\text { von Störfällen } \\
\text { war somit zu } \\
\text { keinem Zeitpunkt } \\
\text { gefährdet. }\end{array}$ & $\begin{array}{l}\text { Por tanto la_ } \\
\text { integridad de } \\
\frac{\text { los objetivos }}{\text { de protección/ }} \\
\frac{\text { el control de }}{\underline{\text { accidentes no }}} \\
\text { estaban en pe- } \\
\text { ligro en ningún } \\
\text { momento. }\end{array}$ & $\begin{array}{l}\text { Así, el cumpli- } \\
\text { miento de los } \\
\text { objetivos de } \\
\text { protección/ } \\
\text { control de ac- } \\
\text { cidentes no se } \\
\text { vio comprome- } \\
\text { tido en ningún } \\
\text { momento. }\end{array}$ \\
\hline
\end{tabular}

Finalmente, en el Ejemplo 10 encontramos nuevamente una traducción aceptable para Niederhaltefeder, pero en el caso de betroffene Federdrahtcharge la traducción es parcialmente 
Ejemplo 10

\begin{tabular}{|c|c|c|}
\hline $\mathrm{DE}$ & ES & TA \\
\hline $\begin{array}{l}\text { Untersuchun- } \\
\text { gen an einer } \\
\text { Niederhalte- } \\
\text { feder aus der } \\
\text { betroffenen } \\
\text { Federdraht- } \\
\text { charge 240719 } \\
\text { aus dem Tro- } \\
\text { ckenlager des } \\
\text { Kernkraftwer- } \\
\text { kes Brokdorf } \\
\text { und an einer } \\
\text { Niederhalte- } \\
\text { feder aus der } \\
\text { Federdraht- } \\
\text { charge 142080 } \\
\text { aus dem } \\
\text { Trockenlager } \\
\text { des Kernkraft- } \\
\text { werkes Gra- } \\
\text { fenrheinfeld } \\
\text { ergaben keine } \\
\text { maßgebenden } \\
\text { zusätzlichen } \\
\text { Informationen } \\
\text { zur Schadens- } \\
\text { ursache. }\end{array}$ & $\begin{array}{l}\text { Las pruebas de } \\
\text { un resorte de } \\
\text { sujeción del lote } \\
\text { de alambre de } \\
\text { resorte afectado } \\
240719 \text { del al- } \\
\text { macén en seco } \\
\text { de la central } \\
\text { nuclear de Brok- } \\
\text { dorf, así como } \\
\text { de un resorte de } \\
\text { sujeción del lote } \\
\text { de alambre de } \\
\text { resorte } 142080 \\
\text { del almacén en } \\
\text { seco de la cen- } \\
\text { tral nuclear de } \\
\text { Grafenrheinfeld } \\
\text { no proporciona- } \\
\text { ron informacio- } \\
\text { nes adicionales } \\
\text { de importancia } \\
\text { sobre la causa } \\
\text { de los daños. }\end{array}$ & 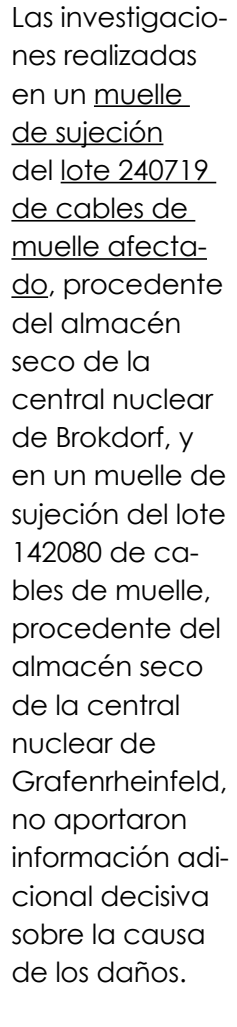 \\
\hline
\end{tabular}

incorrecta, pues "cables de muelle" no resulta comprensible en esta ocasión.

Por lo que respecta a los verbos, en el Ejemplo 11 se ha realizado una interpretación correcta de

Ejemplo 11

\begin{tabular}{|c|c|c|}
\hline $\mathrm{DE}$ & ES & TA \\
\hline $\begin{array}{l}\text { Die gesicherte } \\
\text { Nebenkühlwas- } \\
\text { serpumpe VE1 } 1 \\
\text { D00 I und die } \\
\text { Notnebenkühl- } \\
\text { wasserpumpe } \\
\text { VE12 D001, die } \\
\text { sich im gleichen } \\
\text { Pumpenraum } \\
\text { befindet, } \\
\text { wurden elekt- } \\
\text { risch unscharf } \\
\text { geschaltet. }\end{array}$ & $\begin{array}{l}\frac{\text { Se realizó un }}{\text { descargo }} \\
\text { eléctrico de } \\
\text { la bomba de } \\
\text { agua de refrige- } \\
\text { ración esencial } \\
\text { VE1 } 1 \text { D001 y de } \\
\text { la bomba de } \\
\text { agua de refrige- } \\
\text { ración esencial } \\
\text { de emergencia } \\
\text { que se encuen- } \\
\text { tra en el mismo } \\
\text { cubículo. }\end{array}$ & $\begin{array}{l}\text { La bomba } \\
\text { de agua de } \\
\text { refrigeración } \\
\text { auxiliar asegu- } \\
\text { rada VE1 I D001 } \\
\text { y la bomba de } \\
\text { agua de refri- } \\
\text { geración auxi- } \\
\text { liar de emer- } \\
\text { gencia VE12 } \\
\text { D001, que se } \\
\text { encuentra en la } \\
\text { misma sala de } \\
\text { bombas, se han } \\
\text { desarmado } \\
\text { eléctricamente. }\end{array}$ \\
\hline
\end{tabular}

unscharf schalten, pero el término "desarmar" no sería el convencional en este contexto, por lo que podría causar extrañeza. Del mismo modo, el tiempo verbal no resulta del todo correcto, ya que al tratarse de un informe completo de una medida ya concluida es preferible emplear el pretérito perfecto simple en lugar del compuesto.

El Ejemplo 12, se ha traducido correctamente el verbo instandsetzen pero se ha malinterpretado el término polisémico Anlage como "planta" en lugar de "sistema".

Ejemplo 12

\begin{tabular}{|c|c|c|}
\hline DE & ES & TA \\
\hline $\begin{array}{l}\text { Die betroffenen } \\
\text { Komponenten } \\
\text { der Abwasser- } \\
\text { Verdampfer- } \\
\text { anlage und } \\
\text { der Turbinen- } \\
\text { ölversorgung } \\
\text { wurden auf ihre } \\
\text { Funktionsfähig- } \\
\text { keit überprüft } \\
\text { und soweit } \\
\text { erforderlich } \\
\text { instandgesetzt. }\end{array}$ & $\begin{array}{l}\text { Se comprobó la } \\
\text { funcionalidad } \\
\text { de los compo- } \\
\text { nentes afecta- } \\
\text { dos del sistema } \\
\text { de evaporación } \\
\text { de residuos } \\
\text { industriales y del } \\
\text { suministro de } \\
\text { aceite de la tur- } \\
\text { bina y se realizó } \\
\text { una reparación } \\
\text { en los casos } \\
\text { necesarios. }\end{array}$ & $\begin{array}{l}\text { Se comprobó } \\
\text { el funciona- } \\
\text { miento de los } \\
\text { componentes } \\
\text { afectados de } \\
\text { la planta de } \\
\text { evaporación de } \\
\text { aguas residua- } \\
\text { les y del sumi- } \\
\text { nistro de aceite } \\
\text { de la turbina } \\
\text { y se repararon } \\
\text { en la medida } \\
\text { necesaria. }\end{array}$ \\
\hline
\end{tabular}

En el Ejemplo 13, si bien la traducción "fluir" es parcialmente comprensible, no es la adecuada en este contexto por tratarse de un circuito de agua. La traducción literal de la colocación gefüllte Hochpunkte tampoco resulta del todo comprensible.

\begin{tabular}{|c|c|c|}
\hline $\mathrm{DE}$ & ES & TA \\
\hline $\begin{array}{l}\text { Sie sind immer } \\
\text { dann nicht ver- } \\
\text { meidbar, wenn } \\
\text { die gefüllten } \\
\text { Hochpunkte } \\
\text { länger nicht } \\
\text { durchströmt } \\
\text { werden. }\end{array}$ & $\begin{array}{l}\text { Son inevitables } \\
\text { en los casos en } \\
\text { que el agua } \\
\text { de los puntos } \\
\text { elevados lleva } \\
\text { un tiempo sin } \\
\text { circular. }\end{array}$ & $\begin{array}{l}\text { Siempre son } \\
\text { inevitables si } \\
\text { los puntos altos } \\
\underline{\text { lenos no fluyen }} \\
\text { durante un pe- } \\
\text { ríodo de tiempo } \\
\text { más largo. }\end{array}$ \\
\hline
\end{tabular}

En el Ejemplo 14, la traducción automática del verbo ablassen presenta en realidad un mejor registro que la traducción humana; por el 
Ejemplo 14

\begin{tabular}{|c|c|}
\hline $\mathrm{DE}$ & ES \\
\hline $\begin{array}{l}\text { Bei der Revision bzw. Kontrolle der } \\
\text { Wasserkammern der Gesicherten } \\
\text { Zwischenkühler im Dieselgebäude } \\
\text { wird das Kühlwasser (PE bzw. ve) } \\
\text { abgelassen, wobei die Absperr- } \\
\text { klappen vor und nach dem Kühler } \\
\text { geschlossen werden. }\end{array}$ & $\begin{array}{l}\text { Durante la inspección y el control de } \\
\text { los compartimientos de agua de los } \\
\text { enfriadores intermedios dentro del } \\
\text { edificio de los diésel se vacía el agua } \\
\text { de refrigeración (PE / VE), para lo cual } \\
\text { se cierran las válvulas de aislamien- } \\
\text { to aguas arriba y aguas abajo del } \\
\text { enfriador. }\end{array}$ \\
\hline
\end{tabular}

TA

Cuando se inspeccionan o revisan las cámaras de agua de los enfriadores intermedios asegurados en el edificio de diésel, se drena el agua de refrigeración ( $P E O \mathrm{OV}$ ), para lo cual se cierran las válvulas de cierre antes y después del enfriador. contrario, vuelve a malinterpretarse gesichert como "asegurados", y la traducción de Dieselgebäude es pragmáticamente incorrecta, ya que se trata de un edificio donde están alojados los motores diésel y no el diésel.
Finalmente, en el Ejemplo 15 la traducción del verbo unterstellen es correcta, si bien el orden de la frase y el registro pueden resultar parcialmente confusos.

\begin{tabular}{|c|c|c|}
\hline $\mathrm{DE}$ & ES & TA \\
\hline $\begin{array}{l}\text { Wird gleichzeitig bei Unver- } \\
\text { fügbarkeit einer VE-Pumpe } \\
\text { VE1 1/21/31/41D001 ein Störfall unter- } \\
\text { stellt, bei dem das ve-System zur } \\
\text { Nachwärmeabfuhr und zur Kühlung } \\
\text { von sicherheitstechnisch wichtigen } \\
\text { Komponenten benötigt wird, dann } \\
\text { ist der Ausfall des Stranges als Einzel- } \\
\text { fehler zu betrachten. }\end{array}$ & $\begin{array}{l}\text { Si se postula que simultáneamente } \\
\text { con la inoperabilidad de una bomba } \\
\text { del VE ve1 1/21/31/41D001 se produce } \\
\text { un accidente en el cual se necesita } \\
\text { el sistema ve para la evacuación de } \\
\text { calor residual y para la refrigeración } \\
\text { de componentes importantes para } \\
\text { la seguridad, deberá considerarse el } \\
\text { fallo de un tren como fallo único. }\end{array}$ & $\begin{array}{l}\text { Si, al mismo tiempo, no se dispone } \\
\text { de una bomba VE1 1/21/31/41D001 } \\
\text { y se supone una avería en la que el } \\
\text { sistema ve es necesario para la eli- } \\
\text { minación del calor residual y para } \\
\text { la refrigeración de los componen- } \\
\text { tes importantes para la seguridad, } \\
\text { el fallo de la línea debe considerar- } \\
\text { se como un fallo único. }\end{array}$ \\
\hline
\end{tabular}

A modo de resumen, en la Tabla 12 se han detectado los siguientes aciertos y errores (totales o parciales) en las traducciones automáticas de los fragmentos seleccionados.

\section{Conclusiones}

El presente trabajo, no obstante las limitaciones de su extensión y alcance, ha podido establecer algunas conclusiones preliminares en torno a la traducción del lenguaje técnico del alemán al español. Los rasgos de la terminología técnica en alemán descritos en las fuentes bibliográficas han podido ser identificados

Tabla 12. Resumen de errores y aciertos de la TA.

\begin{tabular}{|l|l|l|}
\hline Categoría & Aciertos & Errores \\
\hline Términos individuales & 2 & 15 \\
\hline Términos multipalabra & 2 & 7 \\
\hline Verbos & 2 & 3 \\
\hline
\end{tabular}

en el corpus de circulares y valoraciones de experiencia operativa en el ámbito de las centrales nucleares. Aquí es de destacar que la terminología presenta numerosas variaciones en cuanto a las convenciones en el uso de siglas, así como de colocaciones o términos multipalabra, polisemia y otros fenómenos, que dan cuenta así de la complejidad que comporta este lenguaje frente a la concepción generalizada de que es mayoritariamente homogéneo y unívoco. La productividad de la lengua alemana a la hora de construir términos compuestos no se limita al sustantivo, sino que abarca también los adjetivos (que igualmente pueden cumplir una función adverbial) y ocasionalmente las formas verbales, lo que resulta en compuestos sintagmáticos de gran extensión en español. Esto hace que en la traducción a esta lengua haya que mantener un dificil equilibrio entre la precisión terminológica y la excesiva repetición en el texto meta, por lo que 
debe elegirse cuidadosamente cuándo es posible realizar una elisión parcial de un término, si bien la tendencia en este género textual será omitir lo menos posible en aras de la total claridad.

En el campo de la tecnología nuclear, la terminología está fuertemente convencionalizada y es conveniente recurrir a los textos paralelos y glosarios específicos que describimos en Castillo (2016), puesto que un sinónimo parcial no cumple las expectativas del receptor. Los informes que componen el corpus aquí estudiado tienen un registro lingüístico elevado, pero la terminología empleada es igualmente aplicable a otros géneros textuales como pueden ser las instrucciones de trabajo o las especificaciones técnicas, si bien en estos últimos cabe esperar variaciones en cuanto a las abreviaturas, las estructuras morfosintácticas, etc.

Con respecto a la traducción automática, la calidad de las traducciones obtenidas es media, ya que se han detectado algunos problemas en el orden de la frase o la interpretación de ciertos elementos fraseológicos, pero sobre todo en el uso de sinónimos parciales y el incumplimiento de las convenciones del género. Se ha detectado un menor número de errores en la traducción de formas verbales, un número medio-alto en la traducción de términos multipalabra y un elevado número de inadecuaciones en los términos individuales. De esta manera, puede afirmarse que el resultado de la traducción automática podría aplicarse con fines informativos, pero nunca con un propósito como el del género textual que aquí presentamos, que es servir de base para elaborar informes sobre seguridad nuclear, ya que requeriría por parte del receptor un esfuerzo de adaptación de la terminología y la fraseología que corresponde al papel del traductor. La labor de posedición dependerá, por tanto, de la familiarización del traductor con la terminología del sector, ya que un excesivo tiempo de comprobación de términos iría contra el propósito del empleo de la traducción automática: optimizar y acelerar la labor traductora.

305

En lo tocante al uso de Sketch Engine, se trata de una herramienta útil por las múltiples opciones de búsqueda que permite, pero la extracción cuantitativa de datos debe compaginarse con el análisis cualitativo para poder descartar errores en la extracción (colocaciones o formas verbales) y para obtener el máximo beneficio del corpus compilado. Se hace patente la necesidad de compilar corpus técnicos porque las unidades terminológicas complejas y altamente especializadas a menudo están ausentes de los diccionarios y glosarios disponibles. En este sentido, la metodología aquí propuesta es especialmente aplicable a la didáctica de la enseñanza especializada, ya que los diversos pasos seguidos (compilación del corpus, alineación semiautomática y manual de los textos, análisis de los términos extraídos y análisis contrastivo de las inadecuaciones de la traducción automática) permiten ampliar paulatinamente la competencia lingüística y traductora.

En futuros trabajos, se ampliará la investigación a todos los tipos de unidades fraseológicas propias del lenguaje técnico alemán y su traducción al español, así como a otros géneros textuales especializados que permitan observar fenómenos más amplios, tales como la variación lingüística diafásica y diastrática.

\section{Referencias}

Arntz, R. (2001). Fachbezogene Mehrsprachigkeit in Recht und Technik. Georg Olms.

Arntz, R. y Picht, H. (1991). Einführung in die Terminologiearbeit. Georg Olms.

Baker, M. (1993). Corpus linguistics and translation studies: Implications and applications. En M. Baker, G. Francis y E. Tognini-Bonelli (Eds.), Text and technology: In honour of John Sinclair (vol. 64, pp. 233-250). John Benjamins. https://doi.org/10.1075/z.64 
Bautista Becerro, F. (2020). Phraseological variations in medical-pharmaceutical terminology and its applications for English and German into Spanish translations. SciMedicine Journal, 2(1), 22-29. http://dx.doi.org/10.28991/SciMedJ-2020-0201-4

Byrne, J. (2014). Scientific and technical translation explained. A nuts and bolts guide for beginners. Routledge. https://doi. org/10.4324/9781315760391

Cabré Castellví, M. T., Estopà Bagot, R. y Lorente Casafont, M. (1996). Terminología y fraseología. En Actas del v Simposio de Terminología Iberoamericana: Terminología: ciencia y tecnología. RITerm.

Castillo Bernal, P. (2016). La traducción e interpretación especializada en el sector nuclear en España. Skopos, 7, 57-72. https://www.uco.es/ ucopress/ojs/index.php/skopos/article/ view/6898/6471

Eurrutia Cavero, M. (2002). La redacción científico-técnica: normas de buen estilo en lengua francesa. Anales de Filología Francesa, 10, 37-56. https://revistas.um.es/analesff/article/ view/19251

Fluck, H.-R. (1997). Fachdeutsch in Naturwissenschaft und Technik. Julius Groos.

Gamero Pérez, S. (2001). La traducción de textos técnicos. Descripción y análisis de textos (alemán-español). Ariel.

Göpferich, S. (1995). Textsorten in Naturwissenschaften und Technik: Pragmatische Typologie, Kontrastierung, Translation. Narr.

Jiménez Serrano, Ó. (2002). La traducción técnica inglés-español: didáctica y mundo profesional. Comares.

Jumpelt, R. W. (1961). Die Übersetzung naturwissenschaftlicher und technischer Literatur. Schöneberg.

Maillot, J. (1997). La traducción científica y técnica. (J. Sevilla Muñoz, trad., obra original publicada en 1969). Gredos.
Müller, S. C. (2018). Deutsch-spanische Terminologie der Energieeffizienz in der Gebäudetechnologie. Redit, Revista Electrónica de Didáctica de la Interpretación y la Traducción, 12, 44-70.

Navarro, F. A. (1997). Traducción y lenguaje en medicina. Ediciones Doyma S. A. https:// cvc.cervantes.es/lengua/hieronymus / pdf/06_07/06_07_169.pdf

Olohan, M. (2016). Scientific and Technical Translation. Routledge. https://doi. org/10.4324/9781315679600

Pinchuck, I. (1977). Scientific and technical translation. André Deutsch.

Reinhardt, W. (Ed.), Frey, C., Köhler, C., KrachtHelbig, G., Peschka, H. y Schütze, R. (1978, segunda edición). Deutsche Fachsprache der Technik. Ein Ratgeber für die Sprachpraxis. vEB.

Sevilla Muñoz, M. (2015). Las unidades fraseológicas del discurso científico-técnico y su traducción (inglés-español). En G. Conde Tarrío, P. Mogorrón Huerta y D. Prieto García-Seco (Eds.), Enfoques actuales para la traducción fraseológica y paremiológica: ámbitos, recursos y modalidades (pp. 239-259). Centro Virtual Cervantes, Instituto Cervantes.

Sturm, S. y Pradas Macías, M. (2015). Contaminación por la lengua origen en la traducción de textos técnicos: el caso de las energías renovables del alemán al español. En M. A. Recio-Ariza, B. Santana-López y M. C. Recio (Eds.), Wechselwirkungen: Überlegungen zur Translationswissenschaft im Sprachenpaar Spanisch-Deutsch. (Serie: Studien zur romanischen Sprachwissenschaft und interkulturellen Kommunikation, vol. 103, pp. 563-580). Peter Lang. https://doi.org/10.3726/978-3-65305424-8/10

Zafio, M. N. (1996). L'adjectif «technique » : au-delà de la polysémie, l'histoire de l'évolution d'une attitude. TTR, 9(2), 193-212. https://doi.or$\mathrm{g} / 10.7202 / 037265 \mathrm{ar}$

Cómo citar este artículo: Castillo Bernal, M. P. (2021). Terminología y fraseología del texto técnico en alemán: características y problemas en la aplicación de la traducción automática. Mutatis Mutandis, Revista Latinoamericana de traducción, 14(2), 285-306. https://doi.org/10.17533/udea.mut.v14n2a02 